\title{
DESCOMPOSICIÓN DUAL DE R2 EN MODELOS DE REGRESIÓN LINEAL
}

\section{Ernesto Cupé Clemente}

\section{RESUMEN}

Se presenta una novedosa técnica de descomposición de $R^{2}$ en modelos de regresión lineal. Se parte del hecho que $R^{2}$ es invariante ante rotaciones coplanares de los vectores de observaciones de las variables, por lo que resulta natural descomponer $R^{2}$ simultáneamente respecto a las direcciones de mayor varianza tanto en el espacio de las variables como de los individuos, lo que conduce a la Descomposición Dual de $R^{2}$. Esta descomposición cuantifica el poder explicativo de cada variable e individuo simultáneamente $\mathrm{y}$, en particular, permite identificar a las variables e individuos de mayor poder explicativo en el modelo. En el primer caso, resulta muy útil para orientar medidas de política; en el segundo, permite identificar individuos atípicos que, cuando concentran demasiado poder explicativo, podrían estar generando lecturas incorrectas para el conjunto. Estos resultados y su aplicación al estudio de determinantes de la distribución de dividendos empresariales, muestran que todo análisis de regresión lineal debería estar acompañado de su respectivo análisis de descomposición dual.

Palabras Clave: Descomposición Dual, Poder Explicativo, Descomposición de Valor Singular, Rotación Coplanar. 